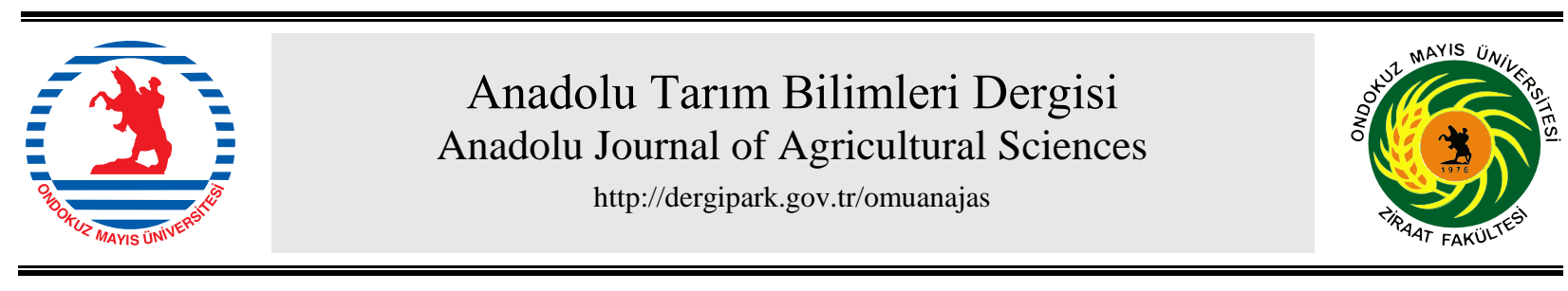

Araştırma/Research

Anadolu Tarım Bilim. Derg./Anadolu J Agr Sci, 32 (2017)

ISSN: 1308-8750 (Print) 1308-8769 (Online)

doi: 10.7161/omuanajas.306199

\title{
Azotlu çözelti ile dip sürgünü temizliğinin fındıkta verim ve meyve kalitesi üzerine etkileri
}

\author{
Ümit Serdar $^{a^{*}}$, Coşkun Gülser ${ }^{\mathrm{b}}$, Burak Akyüz ${ }^{\mathrm{a}}$, Ayşegül Balta $^{\mathrm{c}}$, Yusuf Çil ${ }^{\mathrm{d}}$ \\ Fatma Y1maz Figen $^{\text {d }}$ \\ ${ }^{a}$ Ondokuz Mayıs Üniversitesi, Ziraat Fakültesi Bahçe Bitkileri Bölümü, Atakum, Samsun \\ ${ }^{b}$ Ondokuz Mayıs Üniversitesi, Ziraat Fakültesi Toprak Bilimi ve Bitki Besleme Bölümü, Atakum, Samsun \\ "Çarşamba Tarım İlçe Müdürlüğ̈̈, Çarşamba, Samsun \\ ${ }^{d}$ Agroföy Tarımsal Pazarlamal, Samsun \\ *Sorumlu yazar/corresponding author: userdar@omu.edu.tr
}

Geliş/Received 14/04/2017 Kabul/Accepted 22.06.2017

\begin{abstract}
ÖZET
$\mathrm{Bu}$ araştırmada fındık dip sürgünü temizliğinde azotlu çözelti uygulamalarının verim ve kalite üzerine etkilerinin ortaya konulması amaçlanmıştır. Deneme, Samsun'un Çarşamba ilçesinde çit dikim sistemine sahip üretici bahçesinde "Çakıldak" findık çeşidinde yürütülmüştür. Çalışmada Mart 2016'da bütün ocaklarda findık bıçağı kullanılarak elle dip sürgünü temizliği yapılmıştır. Azotlu çözelti uygulamalarına dip sürgünleri yaklaşık $10-20 \mathrm{~cm}$ boya ulaştığında başlanmıştır. Uygulamalar NisanAğustos ayları arasında 4 defa tekrarlanmıştır. Denemede findık dip sürgünlerine \% 21 Amonyum Sülfat ve \% 26 Kalsiyum Amonyum Nitrat gübrelerinin \% 0, 10, 15 ve 20'lik dozları uygulanmıştır. Fındık dip sürgünü temizliği amacıyla yapılan azotlu çözelti uygulamalarının verim ve meyve kalitesi üzerindeki etkisinin belirlenmesi amaciyla karanfil (dişi çiçek kümesi) sayısı, çotanak sayısı, çotanaktaki meyve sayısı, meyve ağırlığı, iç ağırlığı, iç oranı, kabuk kalınlığı, sağlam iç ve buruşuk iç oranları belirlenmiştir. Araştırma sonucunda azotlu çözelti ile dip sürgünü temizliğinin findıkta karanfil ve çotanak sayıları üzerine olumlu etki yaptığı, ancak meyve kalitesi üzerinde etkili olmadı̆̆ı tespit edilmiştir.
\end{abstract}

The effects of sucker management with nitrogen solution applications on yield and nut quality in hazelnut

\begin{abstract}
The purpose of this study was to determine the effects of nitrogen solution applications in hazelnut sucker management on yield and quality. This study was carried out at an orchard; established with the hedgerow system in Çarşamba district of Samsun province. 'Çakıldak' cultivar was used in the study. Hazelnut suckers were removed by hand with a knife in March, 2016. About 1.5 months later, nitrogen solution applications were started when suckers reached $10-20 \mathrm{~cm}$ in length. Nitrogen solution applications were repeated four times from April to August, 2016. Doses of 0, 10, 15 and $20 \%$ of the solutions for both $21 \%$ ammonium sulphate (AS) and $26 \%$ calcium ammonium nitrate (CAN) were applied. To reveal the effects of this method on yield and quality, number of female flower clusters, number of clusters per shoot, number of nuts per cluster, nut weight, kernel weight, kernel ratio, thickness of the shell, good and wrinkled kernel ratios were determined. As a result of this study, sucker management with nitrogen solution applications positively affected the number of female flowers and number of clusters per shoot. On the other hand, this application didn't affect fruit quality.
\end{abstract}

Anahtar Sözcükler:

Azotlu çözelti

Dip sürgünü temizliği

Findik

Verim

Meyve kalitesi

\section{Giriş}

Fındık, Betulaceae familyası Corylus cinsi içerisinde yer alan sert kabuklu bir meyve türüdür. Ülkemizde findık yetiştiriciliği yoğun olarak Karadeniz bölgesinde yapılmaktadır. Ülkemiz, yıllara göre değişmekle birlikte
400-800 bin ton findık üretimiyle dünya findık üretiminin \% 70'ini, ihracatının ise \% 80'ini karşılamaktadır. Fındık, ülkemizde yaklaşık 500.000 ailenin geçimine katkı sağlamaktadır. 2014 yılı verilerine göre findık üretiminde ülkemizi İtalya (75.456 ton), Gürcistan (37.400 ton), ABD (32.659 ton)

\author{
Keywords: \\ Nut quality \\ Hazelnut \\ Nitrogen solution \\ Sucker control \\ Yield
}

(C) OMU ANAJAS 2017 
ve Azerbaycan (29.796 ton) takip etmektedir (FAOSTAT, 2017). Fındık, ülkemiz için çok önemli bir meyve türü olmasına rağmen findık üretilen illerden büyük şehirlere doğru yoğun bir göç yaşanmıştır. Bu göçün en önemli sebeplerinden biri miras nedeniyle arazilerin parçalanması ve mevcut arazilerin üreticilerin geçimini sağlamaya yetmemesidir. Ülkemizde findık arazileri genellikle meyilli alanlarda bulunmaktadır. Bu durum mekanizasyonu zorlaştırmakta, üretim maliyetinin yüksek olmasına ve üreticilerin findıktan elde ettikleri kârın azalmasına neden olmaktadır. Fındık yetiştiriciliğinin daha kârlı hale getirilebilmesi için yetiştiricilik maliyetlerinin azaltılması gerekmektedir. Fındık yetiştiriciliğinde hasattan sonra en önemli maliyet unsurları fındık dip sürgünü temizliği ve gübrelemedir. Fındık yetiştiriciliğinde dip sürgünlerinin sonbahar ve yaz başında olmak üzere yılda iki defa temizlenmesi önerilmektedir (Okay ve ark., 1986; Beyhan ve ark., 1996; Karadeniz ve ark., 2009). Ancak hem bu işlemin yüksek maliyete sahip olması hem de köylerde genç nüfusun az olması ve istenildiği zaman bu işi yapacak kişilerin bulunamaması nedeniyle dip sürgünü temizliği ancak yılda bir ya da iki yılda bir defa yapılabilmektedir (Kurnaz ve Serdar, 1993; Kılıç ve ark., 2009). Bu durum findık verim ve kalitesini olumsuz yönde etkilemekte ve üreticilerin findıktan elde ettikleri geliri azaltmaktadır. Bazı üreticiler yetiştiricilik maliyetini azaltmak amaciyla yabancı ot ve findık dip sürgünü temizliğinde herbisit kullanmaktadırlar. Ancak herbisit kullanımı hem çevreye zarar vermekte, hem de eğimli arazilerde erozyona neden olmaktadır. Diğer taraftan sürekli herbisit kullanımı toprakta kalıntı bırakma, toprak mikroorganizmaları üzerine olumsuz etkiler yapma ve mevcut ocakların hayatiyetleri için tehdit oluşturma gibi riskler taşımaktadır. Bu nedenle herbisitlere göre daha çevre dostu alternatif metotlara ihtiyaç duyulmuştur. Herbisitlere alternatif kimyasallar olarak azotlu çözeltilerin dip sürgünü temizliğinde uygulanmasıyla ilgili 2014-2015 y1llarında ön çalışmalar yapılmış ve bu çalışmalardan olumlu sonuçlar alınmıştır. Ancak bulunan bu yeni yöntemin findıkta verim ve meyve kalitesi üzerine etkisinin olup olmadığının belirlenmesine de ihtiyaç duyulmuştur.

$\mathrm{Bu}$ çalışmada findık dip sürgünü temizliğinde “azotlu çözelti” uygulamasının findığın verim ve meyve kalitesi üzerine etkisinin ortaya konulması amaçlanmıştır.

\section{Materyal ve Yöntem}

Bu çalı̧̧ma 2016-2017 yılları arasında Samsun'un Çarşamba ilçesinde yürütülmüştür.

\subsection{Materyal}

Çalışma sıra dikim sistemine sahip üretici bahçesinde 'Çakıldak' fındık çeşidi kullanılarak yapılmıştır (Çizelge 1). Çalışmada, sıradaki her 15 dal bir ocak kabul edilmiştir. Araştırmada, findık dip sürgünü temizliği için azotlu çözelti uygulaması yapılmış, bu amaçla \% 21 Amonyum Sülfat ve \% 26 Kalsiyum Amonyum Nitrat gübreleri kullanılmıştır.

Çizelge 1. Deneme bahçesinin özellikleri

Genel özellikler

Toprak özellikleri

\begin{tabular}{cccccccccccc}
\hline $\begin{array}{c}\text { Rakım } \\
(\mathrm{m})\end{array}$ & $\begin{array}{c}\text { Eğim } \\
(\%)\end{array}$ & $\begin{array}{c}\text { Taç yaşı } \\
(\mathrm{y} 1)\end{array}$ & $\begin{array}{c}\text { Bahçe } \\
\text { sistemi }\end{array}$ & $\begin{array}{c}\text { Kil } \\
(\%)\end{array}$ & $\begin{array}{c}\text { Silt } \\
(\%)\end{array}$ & $\begin{array}{c}\text { Kum } \\
(\%)\end{array}$ & $\begin{array}{c}\mathrm{pH} \\
(1: 1)\end{array}$ & $\begin{array}{c}\text { Toplam } \\
\text { tuz } \\
(\%)\end{array}$ & $\begin{array}{c}\text { Fosfor } \\
\left(\mathrm{mg} \mathrm{kg}^{-1}\right)\end{array}$ & $\begin{array}{c}\text { Potasyum } \\
\left(\mathrm{cmol} \mathrm{kg}^{-1}\right)\end{array}$ & $\begin{array}{c}\text { Organik } \\
\text { madde } \\
(\%)\end{array}$ \\
\hline 20 & $0-1$ & 15 & Sira & 63.2 & 24.7 & 12.1 & 7.30 & 0.04 & 24.2 & 0.54 & 2.20 \\
\hline
\end{tabular}

\subsection{Metot}

Mart 2016'da bütün ocaklarda findık bıçağ kullanılarak elle dip sürgünü temizliği yapılmıştır.

Fındık dip sürgünü temizliği amacıyla azotlu çözelti uygulamalarına findık dip sürgünleri yaklaşık $10-20 \mathrm{~cm}$ boya ulaştığında başlanmıştır. Azotlu çözelti uygulamaları Nisan-Ağustos ayları arasında 4 defa tekrarlanmıştır (Çizelge 2).

Denemede findık dip sürgünlerine \% 21 Amonyum Sülfat ve \% 26 Kalsiyum Amonyum Nitrat gübrelerinin $\% 0,10,15$ ve 20 'lik dozları uygulanmıştır. Kontrol uygulamasında (\% 0) çeşme suyu kullanılmıştır. Azotlu çözeltiler findık dip sürgünlerine motorlu pülverizatör ile püskürtülmüştür. Azotlu çözelti uygulamalarında 15 dala sahip alana yaklaşık 1 litre çözelti harcanmıştır. Uygulama sırasında dip sürgünlerinin tamamen 1slatılmasına, bununla birlikte azotlu çözeltilerin meyve veren dallara püskürtülmemesine özen gösterilmiştir.

Denemede her 15 dala sahip alana başlangıçtan itibaren hep aynı uygulama yapılmıştır. Azotlu çözelti uygulamalarının meyve veren dalların verimliliği üzerine etkisinin belirlenmesi amaciyla 2016 yılında çotanak ve çotanaktaki meyve sayısı, 2016 ve 2017 yıllarında ise karanfil (dişi çiçek kümesi) sayısı belirlenmiştir.

Karanfil (dişi çiçek kümesi) sayısı: Şubat ayının ikinci yarısında her ocakta yaklaşı 1-2 cm çapındaki (3-4 yaşl1) 10 sürgünde karanfil sayısı belirlenmiş ve sayım yapılan sürgünün gövde kesit alanına $\left(\mathrm{cm}^{2}\right)$ düşen karanfil sayısı hesaplanmıştır.

Çotanak sayısı: Temmuz sonunda her ocakta yaklaşık 1-2 cm çapındaki (3-4 yaşl1) 10 adet sürgünde çotanak sayısı belirlenmiş ve sayım yapılan sürgünün gövde kesit alanına $\left(\mathrm{cm}^{2}\right)$ düşen çotanak sayısı hesaplanmıştır. 
Çizelge 2. Deneme bahçesinde dip sürgünü temizliği yöntemleri, tarihleri, uygulamalar arasında geçen süre ve uygulama sırasında dip sürgünlerinin boyu $(\mathrm{cm})$

\begin{tabular}{cccc}
\hline $\begin{array}{c}\text { Dip sürgünü } \\
\text { temizliği yöntemi }\end{array}$ & Uygulama tarihi & $\begin{array}{c}\text { Uygulamalar arasında geçen } \\
\text { süre (gün) }\end{array}$ & $\begin{array}{c}\text { Uygulama sırasında dip } \\
\text { sürgünlerinin boyu (cm) }\end{array}$ \\
\hline Fındık bıçağı & 5 Mart 2016 & - & $40-50$ \\
\hline \multirow{3}{*}{ Azotlu çözelti } & 23 Nis 2016 & 44 & $10-20$ \\
& 2 Haz 2016 & 40 & $15-20$ \\
& 7 Tem 2016 & 35 & $20-30$ \\
19 Ağu 2016 & 43 & $25-35$ \\
\hline
\end{tabular}

Çotanaktaki Meyve Sayısı: Derim döneminde her ocaktan tesadüfen seçilmiş 50 çotanakta meyveler sayılarak ortalaması alınmıştır.

Azotlu çözelti uygulamalarının meyve kalitesi üzerine etkisinin belirlenmesi amaciyla 2016 yilında aşağıda belirtilen ölçümler yapılmıştır.

Meyve Ağırlığı: Her ocaktan 100 adet kabuklu meyvede (meyve kuruduktan sonra) hassas terazi ile meyve ağırlığı tartılmış ve ortalama meyve ağırlığı hesaplanmıştır.

İç Ağırlığı: Kabuklu ağırlığı tespit edilen 100 adet meyvenin içi çıkarılarak hassas terazi ile iç ağırlığı belirlenmiş ve ortalama iç ağırlığı hesaplanmıştır.

İç Oranı (\%): Kabuklu ağırlığı tespit edilen 100 adet meyvenin içi çıkarılarak toplam iç ağırlığının toplam kabuklu meyve ağırlı̆̆ına bölünmesiyle hesaplanmıştır. İç Oranı $(\%)=[$ Toplam İç Ağırlı̆̆ $(\mathrm{g}) /$ Toplam Meyve A

Kabuk Kalınlığ 1 (mm): Tesadüfen seçilmiş 30 meyvede, meyvelerin tabla kısmı ile uç kısmının tam ortasındaki kabuk kalınlığı dijital kompas yardımıyla ölçülmüştür.

Sağlam Meyve Oranı (\%): Kabuklu ağırlığı tespit edilen 100 adet meyvenin içi çıkarılarak sağlam ve bütün olanların sayısı toplam kabuklu meyve sayısına bölünerek tespit edilmiştir.
Buruşuk Meyve Oranı (\%): Kabuklu ağırlığı tespit edilen 100 adet meyvenin içi çıkarılarak buruşuk olanların sayıs1 toplam kabuklu meyve sayısina bölünerek tespit edilmiştir.

Çalışma, 2 azotlu çözelti (\% 21 Amonyum Sülfat ve $\% 26$ Kalsiyum Amonyum Nitrat) x $4 \operatorname{doz}(\%$ 0, 10, 15 ve 20) x 3 tekerrür ve her tekerrürde 3 Ocak olmak üzere toplam 72 ocakta yürütülmüştür.

Çalışmamızda tesadüf parselleri deneme deseni kullanılmıştır. Verilerin SPSS istatistik paket programında ANOVA ile analizleri yapılmış ve ortalamalar arasındaki farklılıklar Duncan Çoklu karşılaştırma testi ile belirlenmiştir.

\section{Bulgular ve Tartışma}

Çalışmamızda, gübre çeşitlerinin çotanak sayısı üzerine etkisi istatistiksel olarak önemsiz bulunmuştur (Çizelge 3). Gübre x doz interaksiyonunun çotanak sayısı üzerine etkisi incelendiğinde ise farklı gübre ve dozlarına göre değişken sonuçlar elde edilmiştir. Çotanak sayıs1 en fazla AS-10 ve AS-15 uygulamalarından elde edilmiş̧ir. Çotanaktaki meyve sayısı incelendiğinde ise hem gübre çeşitleri hem de gübre $\mathrm{x}$ doz interaksiyonları arasında istatistiksel olarak önemli bir farklılık saptanmamıştır (Çizelge 3).

Çizelge 3. Meyve veren dallardaki birim kesit alanına çotanak ve çotanaktaki meyve sayıları

\begin{tabular}{lcccc}
\hline & \multicolumn{2}{c}{ Çotanak sayısı $\left({\left.\mathrm{adet} \mathrm{cm}^{-2}\right)}^{2}\right.$} & \multicolumn{2}{c}{ Çotanaktaki meyve sayısı (adet) } \\
\hline Uygulama & Gübre x doz interaksiyonu & Gübre çeşidi & Gübre x doz interaksiyonu & Gübre çeşidi \\
\hline AS-0 & $8.3 \mathrm{ab}$ & & 2.21 & \\
AS-10 & $9.8 \mathrm{a}$ & 8.8 & 2.12 & 2.17 \\
AS-15 & $9.4 \mathrm{a}$ & & 2.26 & \\
AS-20 & $7.8 \mathrm{ab}$ & & 2.07 & 2.01 \\
\hline CAN-0 & $6.9 \mathrm{~b}$ & 8.2 & 2.91 & \\
CAN-10 & $8.0 \mathrm{ab}$ & & 2.12 & 0.07 \\
CAN-15 & $8.8 \mathrm{ab}$ & 0.23 & 1.95 & 0.53 \\
CAN-20 & $9.0 \mathrm{ab}$ & & & \\
\hline Önemlilik & 0.01 & & & \\
\hline
\end{tabular}

Araştırmamızda her iki deneme yılında da gübre çeşitlerinin karanfil sayısı üzerine etkisinin istatistiksel olarak önemsiz olduğu tespit edilmiştir. Gübre x doz interaksiyonları incelendiğinde ise 2016 yılında istatistiksel olarak önemli bir farklılık gözlenmez iken;
2017 yılında gübre dozlarına göre değişken sonuçlar elde edilmiştir. Bununla beraber 2017 yılında karanfil sayısında bazı gübre dozlarında kontrole göre artış saptanmıştır (Çizelge 4). Karanfil sayısı en çok AS-10, CAN-10 ve CAN-20 uygulamalarından elde edilmiştir. 
Çizelge 4. Meyve veren dallardaki karanfil sayıları

\begin{tabular}{lcccc}
\hline \multicolumn{1}{r}{ Y11 } & G016 & \multicolumn{2}{c}{2017} \\
\hline Uygulama & Gübre x doz interaksiyonu & Gübre çeşidi & Gübre x doz interaksiyonu & Gübre çeşidi \\
\hline AS-0 & 14.7 & & $15.5 \mathrm{~b}$ & \\
AS-10 & 14.7 & 14.2 & $24.5 \mathrm{a}$ & 18.0 \\
AS-15 & 16.3 & & $15.6 \mathrm{~b}$ & \\
AS-20 & 11.1 & & $16.3 \mathrm{~b}$ & \\
\hline CAN-0 & 12.7 & 12.0 & $13.9 \mathrm{~b}$ & 21.8 \\
CAN-10 & 11.0 & & $29.4 \mathrm{a}$ & \\
CAN-15 & 11.3 & & $15.1 \mathrm{~b}$ & 0.06 \\
CAN-20 & 12.8 & 0.08 & $29.1 \mathrm{a}$ & 0.00 \\
\hline Önemlilik & 0.12 & & & \\
\hline
\end{tabular}

Araştırmamızda azotlu çözelti uygulamaları sonucunda 2016 yllında çotanak; 2017 yllında ise karanfil sayısında kontrole göre artış saptanmıştır. Fındıkta dip sürgünleri meyve veren dalların besinlerine ortak olmakta, hatta meyve dallarına göre daha kuvvetli gelişme göstererek toprağı sömürmektedir. Çalışmamızda verim özelliklerinde tespit edilen artışların dip sürgünlerinin zamanında ve etkili bir şekilde kontrolü ile sağlandığı kanaatindeyiz. Nitekim fındıkta (fındık bıçağı kullanılarak yapılan) dip sürgünü temizliği sıklığının verim ve meyve kalitesine etkisinin belirlenmesi amacıyla yapmış olduğumuz bir çalışmada yılda bir defa dip sürgünü temizliği uygulaması kontrole göre \% 3.9-17.0 verim artış1 sağlarken, yılda iki defa dip sürgünü temizliği uygulaması kontrole göre \% 27.7-55.9 verim artışı sağlamıştır (Tez, yazım aşamasında). Araştırmamızda azotlu çözelti uygulaması ile findık dip sürgünü temizliğinde gübre çeşidi ile gübre $\mathrm{x}$ doz interaksiyonlarının meyve ağırlı̆̆ı, iç ağırlığı, iç oranı, kabuk kalınlığı, sağlam meyve oranı ve buruşuk meyve oranı üzerine istatistiksel olarak önemli bir farklılık oluşturmadığı saptanmıştır (Çizelge 5-6). .

Çizelge 5. Fındıkların bazı meyve özellikleri

\begin{tabular}{|c|c|c|c|c|}
\hline Uygulama & Meyve ağırlı̆̆ı $(\mathrm{g})$ & İç ağırlı̆ğ (g) & İç oranı $(\%)$ & Kabuk kalınlığı $(\mathrm{mm})$ \\
\hline AS-0 & 1.81 & 0.99 & 54.7 & 0.92 \\
\hline AS-10 & 1.82 & 0.98 & 53.8 & 0.88 \\
\hline AS-15 & 1.72 & 0.93 & 55.4 & 0.82 \\
\hline AS-20 & 1.84 & 1.05 & 57.1 & 0.88 \\
\hline $\mathrm{CAN}-0$ & 1.85 & 1.05 & 56.8 & 0.91 \\
\hline CAN-10 & 1.87 & 1.04 & 55.6 & 0.90 \\
\hline CAN-15 & 1.87 & 1.04 & 55.6 & 0.84 \\
\hline CAN-20 & 1.84 & 1.01 & 54.9 & 0.85 \\
\hline Önemlilik & 0.06 & 0.06 & 0.32 & 0.96 \\
\hline
\end{tabular}

Çizelge 6. Sağlam ve buruşuk meyve oranları

\begin{tabular}{|c|c|c|c|c|}
\hline Uygulama & Sağlam meyve oranı (\%) & \multirow{5}{*}{89.2} & \multicolumn{2}{|c|}{ Buruşuk meyve oranı (\%) } \\
\hline AS-0 & 88.5 & & \multicolumn{2}{|l|}{1.0} \\
\hline AS-10 & 90.5 & & \multicolumn{2}{|l|}{1.8} \\
\hline AS-15 & 86.7 & & 2.3 & \multirow{2}{*}{1.7} \\
\hline AS-20 & 91.3 & & 1.7 & \\
\hline $\mathrm{CAN}-0$ & 90.1 & & 1.4 & \multirow{4}{*}{2.2} \\
\hline CAN-10 & 90.8 & \multirow{3}{*}{91.0} & 3.2 & \\
\hline CAN-15 & 94.6 & & 2.5 & \\
\hline CAN-20 & 88.6 & & 1.8 & \\
\hline Önemlilik & 0.34 & 0.22 & 0.60 & 0.32 \\
\hline
\end{tabular}


Farklılığın gözlenmemesi deneme bahçesindeki tüm bitkilerin bakımlı ve sağlıklı olmasından ileri gelebilir. Nitekim çalışmayı yürüttüğümüz deneme bahçesi verimli bir arazide bulunmakta ve damla sulama ve yaprak gübrelemesi dahil tüm kültürel işlemler zamanında ve titizlikle yürütülmektedir.

\section{Sonuç}

Fındıkta dip sürgünü temizliği etkili bir şekilde yapıldığında verimde önemli artışlar sağlanmaktadır. Araştırmamızda findık dip sürgünü temizliğinin daha kolay ve ekonomik olarak yapılabilmesi için azotlu çözelti uygulamaları yapılmıştır. Çalışmamızda azotlu çözelti uygulamasıyla yapılan dip sürgünü temizliği sonucunda findıkta karanfil ve çotanak sayısında artış sağlanmıştır. Bununla birlikte bu amaçla kullanılan azotlu gübreler arasında verim ve kalite bakımından farklılık bulunmamıştır. Ancak verim ve kalitede olabilecek değişikliklerin uzun yıllar yapılan denemeler sonucunda incelenmesi gerekmektedir. Sonuç olarak, findık dip sürgünü temizliğinde azotlu çözelti uygulamalarının kullanılması önerilebilir.

\section{Teşekkür}

Çalışmamızı maddi olarak TOVAG $115 \mathrm{O} 241$ nolu proje ile destekleyen TÜBİTAK'a teşekkür ederiz.

\section{Kaynaklar}

Beyhan, N., Serdar, Ü. Demir, T., 1996. 2,4-D ve Paraquat'1n fındık dip sürgünü kontrolünde kullanılabilme olanağı. Tarımsal Öğretimin 150. Yıldönümü Fındık ve Diğer Sert Kabuklu Meyveler Sempozyumu, O.M.Ü. Ziraat Fakültesi, s.: 195-204, Samsun,

FAOSTAT. 2017. Dünya findık üretim verileri. URL: http://www.fao.org/faostat/en/\#data/QC/ (Erişim Tarihi:15 Mart 2017).

Karadeniz, T., Bostan, S.Z., Tuncer, C., Tarakçioğlu, C., 2009. Fındık Yetiştiriciliği (1. Basım). Ordu: Ziraat Odaları İl Koordinasyon Kurulu Yayınları No 1.

Kilic, O., Ceyhan, V., Alkan, I., 2009. Determinants of economic efficiency: A case study of hazelnut (Corylus avellana) farms in Samsun Province, Turkey. New Zeal J Crop and Hort., 37: 263-270.

Kurnaz, Ş., Serdar, Ü., 1993. Fatsa ilçesi findık işletmelerinin genel özellikleri, üretim tekniği ve yetiştiricilik sorunları üzerinde bir araştırma. OMÜ Ziraat Fakültesi Dergisi., 8: 114-135.

Okay, A., Kaya, A., Küçük, V., Küçük, A., 1986. Fındık Tarımı. T.C. Tarım Orman ve Köy İşleri Bakanlığı (1. Bask1). Ankara: Tegdem-12. 